\title{
Comprehensive Model of Oxygen Steelmaking Part 1: Model Development and Validation
}

\author{
Neslihan DOGAN, Geoffrey Alan BROOKS and Muhammad Akbar RHAMDHANI \\ Faculty of Engineering and Industrial Science, Swinburne University of Technology, Hawthorn, VIC, 3122 Australia. \\ E-mail: doganeslihan@gmail.com
}

(Received on February 8, 2011; accepted on April 15, 2011)

\begin{abstract}
A comprehensive model of oxygen steelmaking that includes the kinetics of scrap melting, flux dissolution, slag chemistry, temperature profile of the system, formation and residence of metal droplets in the emulsion, and kinetics of decarburization reaction in different reaction zones was developed. This paper discussed the development and the application of the model into an industrial practice. The results from the model were consistent with the plant data from the study of Cicutti et al. The model suggested that $45 \%$ of the total carbon was removed via emulsified metal droplets and the remaining was removed from the impact zone during the entire blow. It was found that the residence time of droplets as well as decarburization reaction rate via emulsified droplets was a strong function of bloating behavior of the droplets. This model is the first attempt in the open literature that allows for the decarburization kinetics of the impact zone to be predicted separately from decarburization kinetics of the emulsion.
\end{abstract}

KEY WORDS: decarburization; bloating; oxygen steelmaking.

\section{Introduction}

Oxygen steelmaking is currently the dominant technology for producing steel from pig iron. The process is complex since it involves simultaneous multi-phase interactions, chemical reactions, heat transfer and complex flow patterns at high temperatures. The transient nature of the process also adds more complexities. The severe operating conditions make it difficult to take measurements and directly observe the process. Furthermore, experimental results are not always adequate in providing an evaluation of important parameters of the system. Mathematical modelling has been widely used to describe the complicated nature of the process; improve understanding of the system and optimise the process control.

There have been a number of process models ${ }^{1-18)}$ developed to describe the kinetics of oxygen steelmaking process with an emphasis on the evolution of bath temperature, metal and slag chemistry. The details of these models are not available in the open literature and they are generally used for internal research requirements at steel plants. Additionally, these models and other previous models represent the system by using practical equations in order to achieve the process control. These simplified models might be suitable for industrial applications and provide reasonable approximations. However, to the authors' knowledge these models ignore the important process variables and changes in process conditions. For example, recent findings such as bloated droplet theory are not included in the previous models.

When the oxygen absorption rate is higher than the rate of consumption of this oxygen at the surface, oxygen builds up in the metal droplet and increases the internal pressure of $\mathrm{CO}$ gas. As the internal pressure of $\mathrm{CO}$ exceeds the surface energy of the metal droplet, $\mathrm{CO}$ gas formation occurs inside metal droplet. ${ }^{19)}$ Once the internal nucleation started, metal droplet becomes "bloated" and surface area increases, therefore, reaction kinetics increases since the turbulence caused by the generation of $\mathrm{CO}$ bubbles inside the metal droplet promotes the mass transfer. ${ }^{20}$ )

Bloating behaviour recognised by Molloseau and Fruehan $^{21)}$ resulted in dramatic affects on the residence time of the droplets which increases up to $120 \mathrm{~s}$. This behaviour has a significant impact on the decarburization rates in the emulsion, thereby the overall kinetics of the oxygen steelmaking process. ${ }^{21,22)}$ Although these models played an important role in the development of holistic model for oxygen steelmaking process, there is still work required for the development of robust and accurate models.

The principle aim of the present study is to develop a comprehensive model of decarburization in oxygen steelmaking. The model focuses on the decarburization reaction in different reaction zones to predict the carbon content of liquid steel throughout the blow and is validated with a set of industrial data. In this Part 1 paper, the development of the global model incorporating the bloated droplet theory will be discussed. The Part 2 and 3 papers, will describe in more details the development and analysis of the sub-models at the emulsion and impact zones. ${ }^{23,24)}$

\section{Model Development}

Since the key objective is to predict the change in concentration of carbon in the liquid bath, a mass balance equation is performed. The change in carbon content of liquid 
iron is the function of amount of scrap melted and amount of carbon removed in each reaction zone and is given in Eq. (1). It should be noted that amount of carbon removed via emulsion phase is added to this equation when the droplets return to the liquid bath.

$$
\begin{aligned}
W_{b}^{t} \frac{{\text { mass } \% C_{b}^{t}}_{100}}{=} & W_{b}^{t-\Delta-} \frac{\operatorname{mass}_{0} C_{b}^{t-\Delta-}}{100}+W_{S c}^{t} \frac{\operatorname{mass} \% C_{s c}}{100} \\
& -\left(\frac{d W_{C}}{d t}\right)_{e m} \Delta t-\left(\frac{d W_{C}}{d t}\right)_{b} \Delta t
\end{aligned}
$$

where $C$ is the carbon concentration, $W_{b}$ is the mass of metal in the bath, $W_{s c}$ is the mass of scrap melted in the bath. The subscripts em refers to emulsion. It should be noted that the amount of carbon removed via emulsion represents the amount of carbon removed via metal droplets returning to the liquid bath. The metal droplets suspended in the emulsion phase have no impact on the overall mass balance of carbon in the bath.

Since the data points for initial and intermediate metal oxide concentrations in the slag phase are known, rate equations are solved with defined process variables and parameters using an explicit function and the change in carbon concentration can be predicted by marching forward with a defined time step, $\Delta t$. At the end of each time step, the new carbon concentration can be calculated and the output results of the model are updated, with values from each subroutine entered as input data for the next time step. The calculation procedure is repeated until the total calculation time is reached for the defined blowing time.

For better understanding the interactions between the phases, the system divided into sub-models and reaction zones. The system includes 17 sub-models and 2 reaction zones. Two reaction zones, namely, the emulsion and impact zone are considered to investigate the kinetics and mechanism of carbon removal reactions since it is well known that these reactions take place via direct oxygen absorption at the impact area and $\mathrm{FeO}$ reduction in the emulsion phase. ${ }^{25)}$ The reaction zones are linked to each other by material streams which are slag constitutes and liquid metal droplets. The input mass flows, process conditions and calculation submodels to be considered for each reaction zone are hot metal, scrap and flux charges, hot metal, scrap and slag compositions, oxygen blowing conditions, lance height, gas flow rates, temperature of the bath, the slag and the impact zones, flux dissolution, scrap melting, ejected metal droplets behaviour such as droplet generation rate, droplet size, residence time in the emulsion, decarburization rates in the emulsion and impact zones and are illustrated in Fig. 1.

Once all the variables deemed to be important to the each sub-model have been identified, inter-relationships among them are developed. These sub-models are built separately and later linked together. They form the whole system to predict the outcome from a set of initial conditions. Several of the sub-models such as flux dissolution and droplet generation that form the global model have been validated against industrial data in the open literature. The results have been published elsewhere. ${ }^{26,27)}$

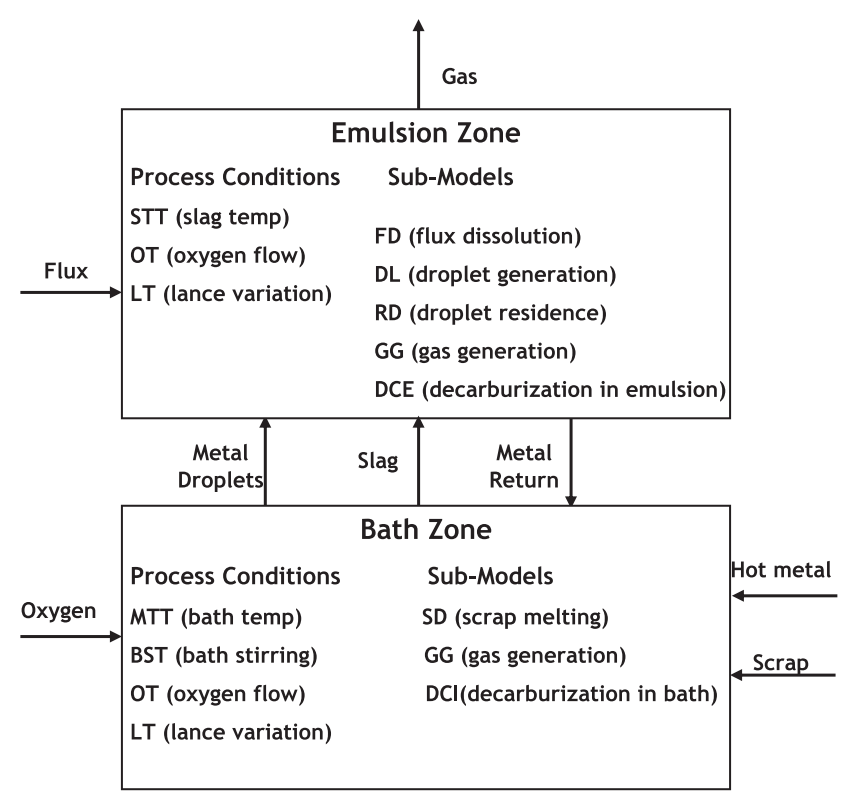

Fig. 1. The schematic description of the system.

\section{Assumptions}

The assumptions for decarburization reactions in each reaction zone are provided in the corresponding paper. The major assumptions included in the mathematical model are as follows.

(1) The amount of heat generated or transfer was not included in this study. The temperature profile of the metal bath was considered to increase linearly as the blowing progresses. Consequently, the temperature of the slag was considered to be $100^{\circ} \mathrm{C}$ higher than that of the metal bath. $^{25,28)}$

(2) The calculations were started at the 2 min after the start of blowing since the available data was started from this moment.

(3) It was assumed that iron ore was dissolved into the liquid iron as it was charged to the furnace. The kinetics of iron ore dissolution was not included in the study since iron ore was added in the first two mins. The dissolution of refractory into the slag phase is complicated and very slow process. It is very difficult to predict the amount of refractory dissolved during one heat. For simplicity, it was not included in this study.

(4) It was assumed that the gas generated by the decarburization reactions was carbon monoxide with $15 \%$ of the generated $\mathrm{CO}$ gas combusted to $\mathrm{CO}_{2}$.

(5) The foamy height of the slag was predicted as a function of the volume of the gas in the furnace in the previous study of the current authors. ${ }^{27)}$ In our previous study, it was predicted that $90 \%$ of the total amount of gas generated leave the process as an off-gas and $10 \%$ of the gas collapse in the emulsion phase. This proportion was related to the maximum height of the foamy slag that can reach where it lied at the edge of slopping. This assumption has been discussed in our previous study. ${ }^{27}$ ) The same assumption was used for the predictions of the global model since this model was a part of the global model.

(6) Some of the metal droplets generated by the oxygen impingement might be entrained by the oxygen jet and 
return to the metal bath; some droplets enter to the slag-gasmetal emulsion and some droplets escape from the emulsion and are ejected from the furnace. In this study, it was assumed that all the droplets were ejected to the emulsion phase. Accordingly, possible reactions between metal droplets ejected from the bath and oxygen or carbon dioxide were neglected in this study.

(7) The model did not consider the refining reactions of other impurities of liquid metal. The amount of major metal oxides such as $\mathrm{FeO}$ and $\mathrm{SiO}_{2}$ present in the slag were taken from the industrial data with respect to blowing time and were entered as an input data for the model calculations.

\section{Computational Solution}

The computational solution was based on a stepwise calculation of carbon removal reaction and it allowed the continuous calculation of the change of carbon in liquid iron and gas composition throughout the oxygen steelmaking process. The basis of global model was the central sub-model where the change in carbon concentration and the weight of the bath were calculated as a function of process variables and parameters considered by initiation of the data required and calculation of crucial parts of the kinetics of the process.

Figure 2 demonstrates the flow computing program for the complete mathematical model. Initially, global parameters such as gas constant, molecular weight of metal oxides and density of lime, lance dynamics, oxygen blowing conditions and furnace charges such as hot metal, scrap and flux additions were entered to the central sub-model as an input. Bath and slag temperatures were calculated to obtain the physical properties of slag and gas phases such as density and viscosity. Droplet generation rate and number of droplets were calculated to be used in decarburization in the emulsion model. Flux dissolution was calculated as a function of composition, temperature and physical properties of slag. Then, the amount of flux dissolved into the slag was used to predict the amount of slag formed. The values from flux dissolution, physical properties of slag and droplet generation sub-models were used to estimate the residence time of droplets. Later, decarburization rate in emulsion was calculated as a function of residence time of droplets. This sub-model also used information from the droplet generation sub-model. After these calculations, scrap melting as a function of bath temperature, enthalpy change in iron and decarburization in impact zone as a function of blowing conditions, gas composition and impact temperature were calculated, respectively. The calculation procedure for scrap melting was briefly provided in Appendix. Using the proposed kinetic models, the decarburization reaction rates in each reaction zone were calculated. In Eq. (1), these rates were substituted to estimate the carbon content of the liquid iron.

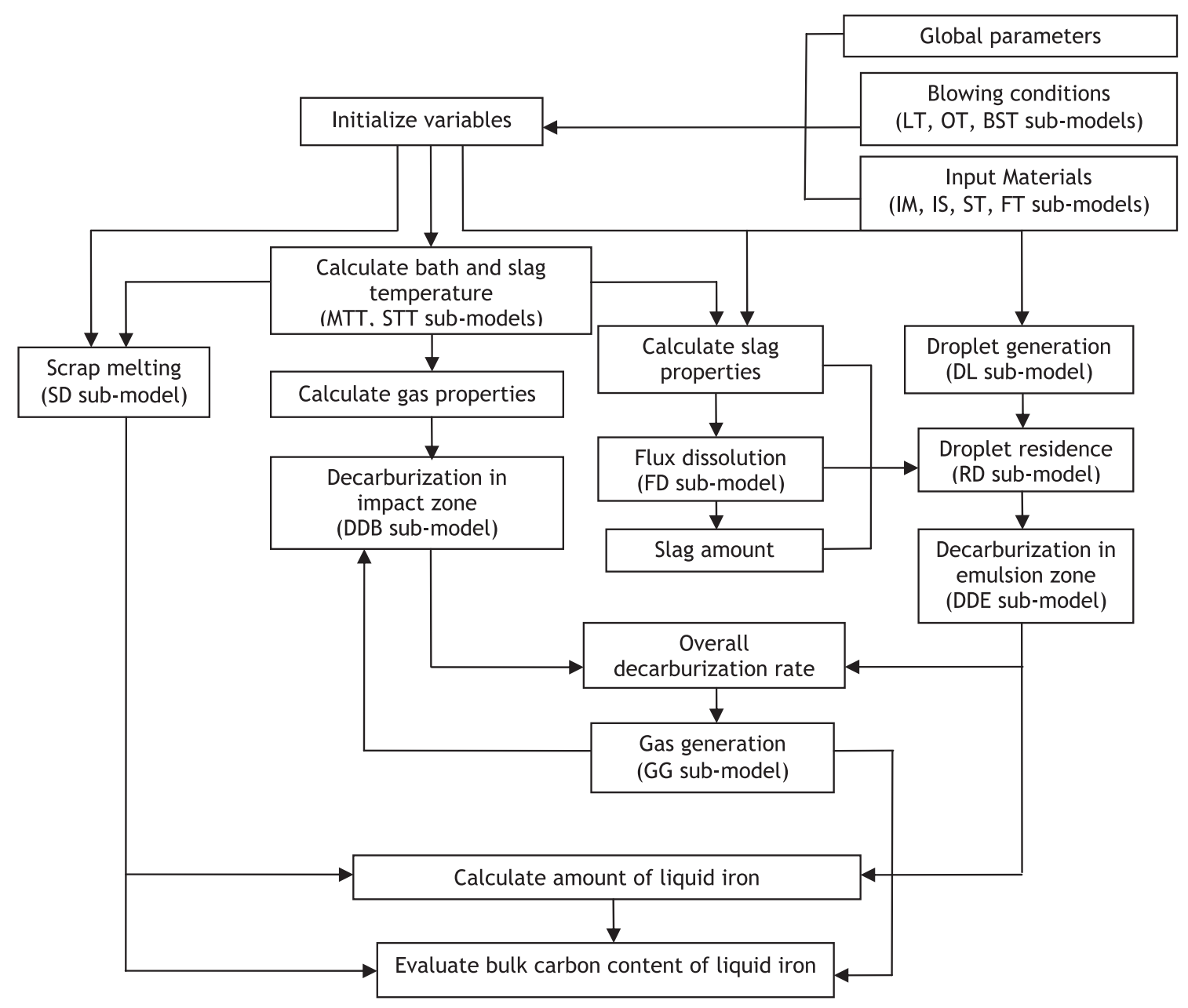

Fig. 2. Global computational mathematical model. 


\section{Input Data}

The program was tested for an industrial data reported by Cicutti et al. ${ }^{29,30)}$ There have been 10 studies which were reviewed by Subagyo et al. ${ }^{31)}$ These studies provide several operating conditions for oxygen steelmaking process. As far as the authors knowledge this is the only study in the literature that provides data on the variation in slag compositions complete with important process parameters such as lance height, metal, scrap and flux charges and compositions and oxygen blowing rate and provides results on droplet size, carbon content of liquid metal and metal droplets, slag weight and overall decarburization curve. Table 1 shows the operating conditions of oxygen steelmaking process taken from the study of Cicutti et $a{ }^{29}{ }^{29}$ In the study of Cicutti et $a l .{ }^{29)}$ the composition variations of slag and metal during the blow were examined by sampling method. Slag and metal samples were taken from the mouth of the furnace at seven different times from the start of the blow. Only one sample was taken by disturbing the blow and submerging the sampler into the furnace. This practice was repeated at least five times for each sampling point. ${ }^{29)}$

\section{Results and Discussion}

\subsection{Verification}

The global model was simulated for various time steps in

Table 1. Data for numerical calculation. ${ }^{29)}$

\begin{tabular}{lc}
\hline Hot metal charged & $170 \mathrm{t}$ \\
Scrap charged & $30 \mathrm{t}$ \\
Oxygen flow rate & $620 \mathrm{Nm}^{3} / \mathrm{min}$ \\
Supply pressure & $1013.25 \mathrm{kPa}$ \\
Number of nozzle & 6 \\
Throat diameter of nozzle & $33 \mathrm{~mm}$ \\
Exit diameter of nozzle & $45 \mathrm{~mm}$ \\
Inclination angle & $17.5^{\circ}$ \\
Lance height & $1.8-2.5 \mathrm{~m}$ \\
Initial hot metal temperature & $1350^{\circ} \mathrm{C}$ \\
Tapping temperature & $1650^{\circ} \mathrm{C}$ \\
\hline
\end{tabular}

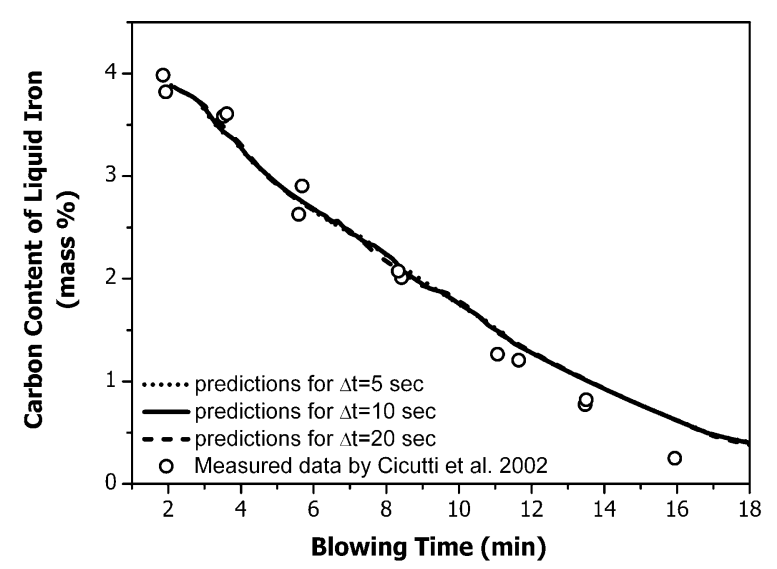

Fig. 3. Change in carbon content of liquid iron with respect to blowing time predicted as a function of various time steps. order to provide an optimal solution. The model cannot be run for smaller than $5 \mathrm{~s}$ time step due to the computational limitations and the simulations using the greater time steps are not able to capture the spontaneous changes within the metal droplets. Accordingly, time steps of 5, 10 and $20 \mathrm{~s}$ are selected and the model predictions of the carbon content of liquid steel as a function of time steps are compared in Fig. 3. The values of decarburization rates for step size, $\Delta t=5,10$, $20 \mathrm{~s}$ converge to each other which proves that the model was programmed accurately. The defined step size of $10 \mathrm{~s}$ is likely to provide better approximations based on the model predictions compared with the industrial data for this calculation. When considering the simplicity of the implementation and computer time requirements, the global model was developed by using the time step of $10 \mathrm{~s}$ for the further calculations. The total calculation time for one blowing period is approximately $4 \mathrm{~h}$ on a PC (Pentium (R) 4 CPU 3.00 $\mathrm{GHz}, 3 \mathrm{~GB}$ of RAM).

\subsection{Validation}

The change in carbon concentration is simulated for each time step based on the overall kinetics of the process in each reaction zones incorporating the defined process variables and parameters. Figure 4 shows the model predictions of carbon content of liquid iron compared to measured data reported by Cicutti et al. ${ }^{29)}$ The predicted model results are in good agreement with those reported by Cicutti et al. This implies that the proposed model based on decarburization in impact and emulsion zones incorporating the bloating droplet theory is successfully applied for a given set of industrial data. As seen in Fig. 4, the model over predicts the end carbon content. This is most likely due to under predicting the decarburization rates in the emulsion or in the impact or in both zones.

The predictions of hot metal, scrap and slag masses with respect to time are given in Fig. 5. The change in the mass of liquid bath can be estimated using the calculated mass of scrap melted at time $t$, amount of slag generated during time step, $\Delta t$, the metal droplets generated through emulsion phase and fallen back to metal bath during time step, $\Delta t$. The relationship is;

$$
W_{b}^{t}=W_{b}^{t-\Delta t}+W_{S c}^{t}-W_{m, g e n}^{\Delta t}+W_{m, \text { returning }}^{\Delta t}-W_{s, \text { gen }}^{\Delta t}
$$

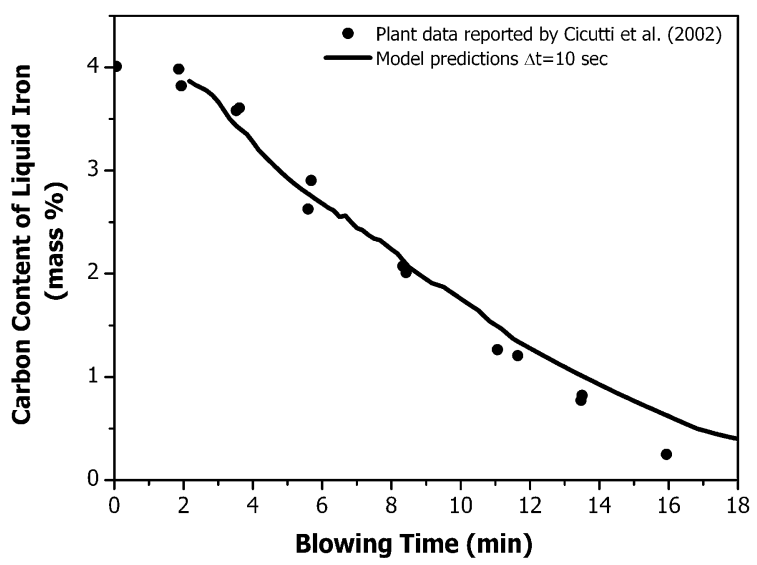

Fig. 4. Computed carbon content as a function of blowing time was compared with the measured data reported by Cicutti et $a .^{29)}$ 


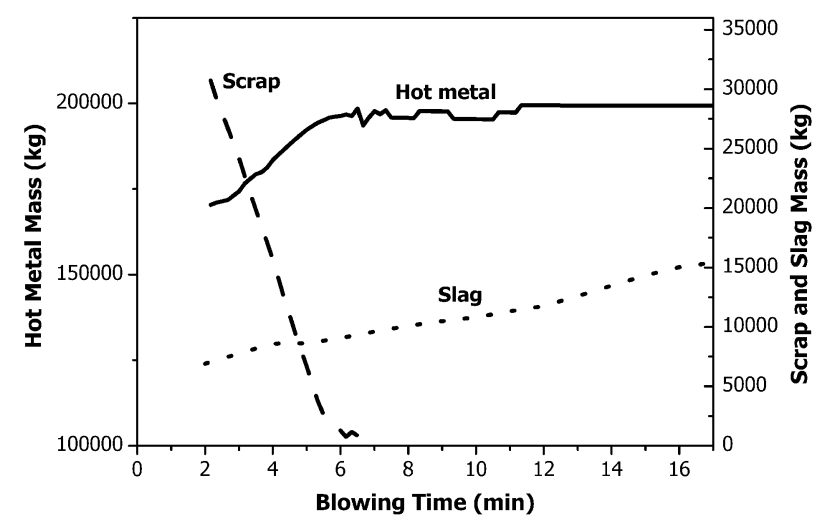

Fig. 5. Evolution of hot metal, scrap and slag mass as a function of time.

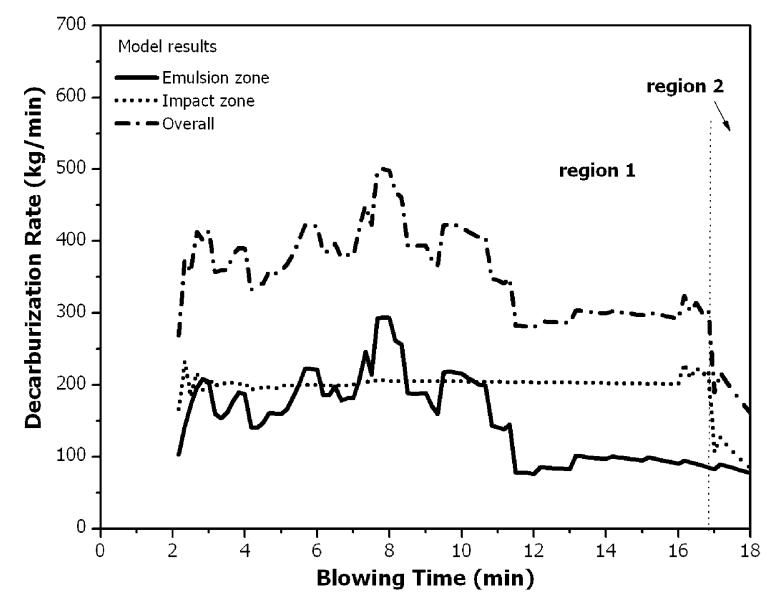

Fig. 6. Comparison of decarburization rate curves at different reaction zones.

In the case of scrap, the values for the amount of scrap melted were obtained from the scrap melting model. The model predicts that the scrap was melted gradually and disappeared at $7 \mathrm{~min}$ after the start of blowing. The flux dissolution model gives the predictions for amount of slag produced throughout the blow. The details of this sub-model has been published in elsewhere. ${ }^{27)}$ Initially (between 2-4 min), slag weight increases linearly and remains almost constant during the time between 5-12 min. Towards the end of the blow, it increases linearly.

\subsection{Decarburization Rates}

The results for the prediction of decarburization rates in the emulsion and impact zones and overall decarburization rate throughout the blow are presented in Fig. 6. The reaction rates are plotted with respect to time. The reaction rates are close to each other in the early blow and then the decarburization rate in the emulsion zone is higher than in the impact zone during the main blow. At the $10 \mathrm{~min}$ after the start of blowing, the decarburization rate in the emulsion zone decreases gradually towards the end of the blow since the metal droplets contain lower carbon contents and they suspend shorter time in the emulsion phase that lowers the reaction rate in the emulsion. Decarburization rates in the emulsion in the range $75-310 \mathrm{~kg}$ carbon removed per min are estimated.

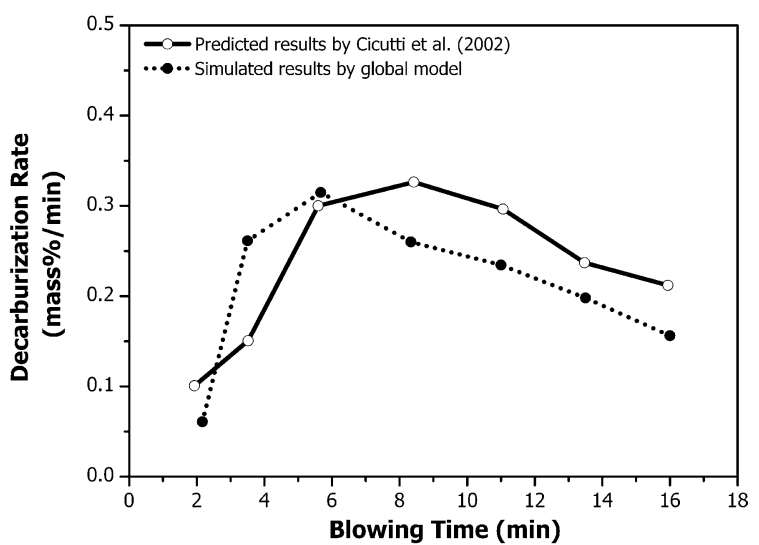

Fig. 7. Overall decarburization curve was compared with the industrial data reported by Cicutti et al. ${ }^{29,30)}$

Alternatively, decarburization rate in the impact zone remains constant up to the point carbon level reaches the critical carbon content. During this period, the values varied from 160 to $230 \mathrm{~kg}$ carbon removed per min with a mean value of $200 \mathrm{~kg} / \mathrm{min}$. There are variations initially due to differences in partial pressure of gasses. As this difference becomes smaller, there is little change in the predicted decarburization rates in the impact zone. It should be noted that this model is likely to overpredict the decarburization rate in the impact zone to some extent since it is assumed that all the oxygen is only used for carbon removal reaction. This assumption is reasonable for main blowing period. However, it should be noted that there are other refining reactions occurring simultaneously.

As discussed in Part 3 paper, critical carbon content is considered to be 0.5 mass $\%$ in this study. In region 1 (above the critical carbon content), the rate of carbon oxidation is independent of carbon concentration but subjected to the fluid flow and partial pressure of gasses. In region 2 , the reaction rate for impact zone decreases sharply due to the low carbon content of liquid bath. The increase at the end of the blow is due to the increase in mass transfer rates in liquid bath by increasing the bottom stirring.

In Fig. 6, it can be seen that there are periodical trends at emulsion zone rates. This finding will be discussed in details in Part 2. It was found that the residence time of droplets is strong function of carbon content of liquid metal droplets and physical properties of the slag. The chemistry and physical conditions of the process changes every min and remains constant for the following calculation procedure. Since the lance height, FeO content of the slag and the slag properties are changing every min, the residence time decreases as the carbon content of the metal decreases for a defined time-step. Therefore, increment points show most likely the increase in decarburization rates as a function of new process conditions defined and followed by a decrease in decarburization rate as the carbon content decreases.

Figure 7 demonstrates the evolution of overall decarburization rate in comparison with the predicted industrial data reported by Cicutti et al. ${ }^{29,30)}$ The overall decarburization rate was calculated as a function of the differences in carbon concentration in liquid iron measured from the seven sampling points over time. The same procedure was used for the 
model predictions to be consistent in the comparison in Fig. 7. The change in carbon concentration of liquid iron was predicted by the model. The predicted results for carbon concentration for the sampling points were extracted and the concentration differences of carbon were calculated over time. The calculation results are in agreement with those reported by Cicutti et al. ${ }^{29)}$ however, towards the end of the blow, the overall decarburization rate was underpredicted due to the low decarburization rates of dense droplets. Based on the model predictions, $45 \%$ of carbon is removed via emulsified metal droplets and remaining is removed from the impact zone. This finding agrees well with Cicutti et $a l{ }^{29)}$ and Price et $a l .{ }^{32)}$

\section{Conclusion}

A dynamic model to simulate the oxygen steelmaking process was developed. A new method was used to calculate the refining reaction within the droplets generated in the emulsion phase using the bloated droplet theory for better understanding the process kinetics. On the basis of this study, it is possible to draw the following conclusions.

(1) A comprehensive model incorporating the bloating behaviour of droplets has been developed and validated against industrial data. The model can predict the variations in the carbon content of liquid iron during the blowing process under the defined operating conditions.

(2) The current approach enables to make the connections with the residence of metal droplets in the emulsion and overall reaction kinetics of oxygen steelmaking process and to make use of these results and provide more insights of "bloating droplet theory" for an industrial practice. The results indicated that the behaviour of droplets has a crucial impact on decarburization kinetics.

(3) The global model enables to compare the decarburization rates in different reaction zones and to provide a better understanding of the process variables affecting in each reaction zone. From the model results, it is suggested that $60 \%$ of decarburization takes place in the emulsion phase during the main blow followed by a decrease to below $30 \%$ towards the end of the blow. We understand that this is the first model in the open literature that allows these comparisons to be made and represent an original contribution to the field.

\section{REFERENCES}

1) S. Asai and I. Muchi: Trans. Iron Steel Inst. Jpn., 10 (1970), 250.

2) E. L. Cambridge, J. R. Middleton and R. Rolls: International Conf. on Science and Technology of Iron and Steel, ISIJ, Tokyo, (1971), 344.

3) I. Muchi, S. Asai and M. Miwa: International Conf. on Science and Technology of Iron and Steel, ISIJ, Tokyo, (1971), 347.

4) J. R. Middleton and R. Rolls: Proc. of the Conf. on Mathematical Process Models in Iron- and Steelmaking, The Metals Society, London, (1973), 117.

5) R. Weeks: Proc. of the Conf. on Mathematical Process Models in Iron- and Steelmaking, The Metals Society, London, (1973), 103.

6) S. Asai and I. Muchi: Trans. Iron Steel Inst. Jpn., 14 (1974), 34.

7) B. Deo, P. Ranjan and A. Kumar: Process Metallurgy, 58 (1987), 427.

8) E. Andersin and H. Jalkanen: Proc. of the 6th Int. Iron and Steel Cong., ISIJ, Tokyo, (1990), 378.

9) W. v. d. Knoop, B. Deo, A. B. Snoijer, G. v. Unen and R. Boom: 4th Int. Conf. on Molten Slags and Fluxes, ISS, Warrendale, PA, (1992), 302 .

10) A. Traebert, M. Modigell, P. Monheim and K. Hack: Scand. J. Metall., 28 (1999), 285.
11) H. Jalkanen and T. Kostamo: Metallurgy Refractories and Environment, M. S. a. E. V. P. PalfyI, Kosice: Harlequin, (2004), 87.

12) B. Deo and V. Balakrishnan: AISTech - Iron and Steel Technology Conf. Proc., AIST, Warrendale, PA, (2009), 801.

13) E. Graveland-Gisolf, P. Mink, A. B. Snoeijer, E. Barker, R. Boom, D. Dixit and B. Deo: The New Generation Slag-Droplet Model, (2007), unpublished work.

14) T. Takawa, K. Katayama, K. Katohgi and T. Kuribayashi: Trans. Iron Steel Inst. Jpn., 28 (1988), 59.

15) C. Chigwedu, J. Kempken and W. Pluschkell: Stahl Essen, 126 (2006), 25.

16) E. Graveland-Gisolf, P. Mink, A. Overbosch, R. Boom, G. d. Gendt and B. Deo: Steel Res., 74 (2003), 125.

17) C. Kattenbelt and B. Roffel: Metall. Mater. Trans. B: Process Metall. Mater. Processing Sci., 39 (2008), 764.

18) M. Modigell, A. Traebert, P. Monheim, S. Petersen and U. Pickartz: Comput. Chem. Eng., 25 (2001), 723.

19) K. Gao, V. Sahajwalla, H. Sun, C. Wheatley and R. Dry: ISIJ Int., 40 (2000), 301.

20) H. Sun and G. Zhang: ICS Proc., ACM, New York, (2005), 257.

$21)$ C. L. Molloseau and R. J. Fruehan: Metall. Mater. Trans. B, 33B (2002), 335.

22) G. A. Brooks, Y. Pan, Subagyo and K. Coley: Metall. Mater. Trans. $B, 36$ (2005), 525.

23) N. Dogan, G. A. Brooks and M. A. Rhamdhani: ISIJ Int., 51 (2011), 1093.

24) N. Dogan, G. A. Brooks and M. A. Rhamdhani: ISIJ Int., 51 (2011), 1102.

25) B. Deo and R. Boom: Fundamentals of Steelmaking Metallurgy, Prentice Hall Int., New York, (1993), 21.

26) N. Dogan, G. A. Brooks and M. A. Rhamdhani: ISIJ Int., 49 (2009), 24.

27) N. Dogan, G. A. Brooks and M. A. Rhamdhani: ISIJ Int., 49 (2009), 1474.

28) A. Masui, K. Yamada and K. Takahashi: McMaster Sympo., McMaster University, Hamilton, Canada, (1976), 1.

29) C. Cicutti, M. Valdez, T. Perez, J. Petroni, A. Gomez, R. Donayo and L. Ferro: 6th Int. Conf. on Molten Slags, Flux Salts, ISS, Warrendale, PA, (2000), 367.

30) C. Cicutti, M. Valdez, T. Perez, R. Donayo and J. Petroni: Latin Am. Appl. Res., 32 (2002), 237.

31) Subagyo, G. A. Brooks and K. S. Coley: Ironmaking Conf. Proc., ISS, Warrendale, PA, USA, (2002), 837.

32) D. J. Price: Process Engineering of Pyrometallurgy Symposium, IMM, London, (1974), 8.

33) G. Sethi, A. K. Shukla, P. C. Das, P. Chandra and B. Deo: AISTech 2004 Proc., AIST, Warrendale, PA, (2004), 915.

34) H. W. d. Hartog, P. J. Kreyger and A. B. Snoeijer: C.R.M, 37 (1973), 13.

35) H. Gaye, M. Wanin, P. Gugliermina and P. Schittly: Proc. of the 68th Steelmaking Conf., AIME, Littleton, CO, (1986), 793.

36) G. H. Geiger and D. R. Poirier: Transport Phenomena in Material Processing, AIME, Warrendale, PA, (1994), 298.

37) G. Sethi, A. K. Shukla, P. C. Das, P. Chandra and B. Deo: AISTech 2004 Proc., AIST, Warrandale, PA, (2004), 915.

38) J. Szekely, Y. K. Chuang and J. W. Hlinka: Metall. Mater. Trans. B, 3 (1972).

39) J. K. Wright and I. F. Taylor: ISIJ Int., 33 (1993), 529.

40) E. Specht and R. Jeschar: Wärme- und Stoffübertragung, 18 (1984), 75.

41) H. Gaye, P. Destannes, J. L. Roth and M. Guyon: Proc. of the 6th Int. Iron and Steel Cong., ISIJ, Tokyo, (1990), 11.

42) L. Gu and G. A. Irons: 55th Electric Arc Furnace Conf. Proc., ISS, Warrendale, PA, (1997), 651.

43) L. Gu and G. A. Irons: Electric Arc Furnace Conf. Proc., ISS, Warrendale, PA, (1999), 269.

44) J. Li, N. Provatas and G. A. Brooks: Metall. Mater. Trans. B, 36B (2005), 293.

45) J. Li and N. Provatas: Metall. Mater. Trans. B, 39 (2008), 268.

\section{Appendix}

\section{Scrap Melting}

The kinetic model developed by Sethi et al. ${ }^{33)}$ was applied in this study since it was relatively easier to apply compared to the other available models. ${ }^{34,35)}$ In the mathematical model, the heat conservation equation was solved to calculate the melting behaviour of scrap in the liquid metal. The equation was:

$$
h A\left(T_{b}-T^{\prime}\right)=\rho A\left(-\Delta H_{F e}\right) v-\left.\lambda A \frac{\partial T_{s c}}{\partial x}\right|_{i n t}
$$


where $h$ is heat transfer coefficient, $\lambda$ is heat conductivity, $A$ is surface area of scrap and $\rho$ is the density of scrap. Enthalpy change in scrap melting and raising the temperature of liquid metal to interface temperature is equal to $\Delta H_{\mathrm{Fe}}$. This relationship is given using:

$$
\Delta H_{F e}=\Delta h+C p_{m}\left(T_{b}-T^{\prime}\right)
$$

The temperature at interface, $T^{\prime}$, was related to the interface carbon concentration referring to the $\mathrm{Fe}-\mathrm{C}$ phase diagram using:

$$
\begin{array}{r}
T^{\prime}=1810-90 C^{\prime}, \quad 0 \leq C^{\prime} \leq 4.27 \% \\
T^{\prime}=1425, \quad C^{\prime}>4.27 \% \ldots \ldots \ldots .
\end{array}
$$

Here $C^{\prime}$ and $T^{\prime}$ denote carbon concentration and scrap temperature at the interface. For one dimensional heat flow, the temperature distribution across the scrap at a given time step can be obtained by employing the Fourier series. In this study, the temperature distribution of the scrap was estimated calculated using the error function, which is simple to apply and valid for calculations over short time steps. ${ }^{36)}$

Heat convection was calculated as a function of bath temperature and interface temperature of scrap whereas heat conduction was calculated as a function of interface temperature of scrap-metal, scrap temperature and thermal conductivity of scrap. The heat convection and the heat conduction were compared. If the heat conduction is much higher than heat convection, solidification takes place. Conversely, melting takes place.

The melting rate of scrap was calculated as a function of temperature profile of the scrap and carbon concentration of the metal bath. The heat transfer coefficient was assumed to be constant. Figure 8 compares the values for scrap thickness as a function of time predicted by the modified model with the study of Sethi et al. ${ }^{37)}$ The results are in agreement with the previous study that can be applicable for other industrial applications. It should be noted that heat transfer coefficient should be modified. Heat transfer coefficients can be estimated from experimental studies using dimensionless analysis technique. ${ }^{38,39)}$ However, this approach is likely not to be valid for oxygen steelmaking where the velocity fields are complex and not homogenous (e.g. some parts of the slag near the furnace walls maybe comparatively

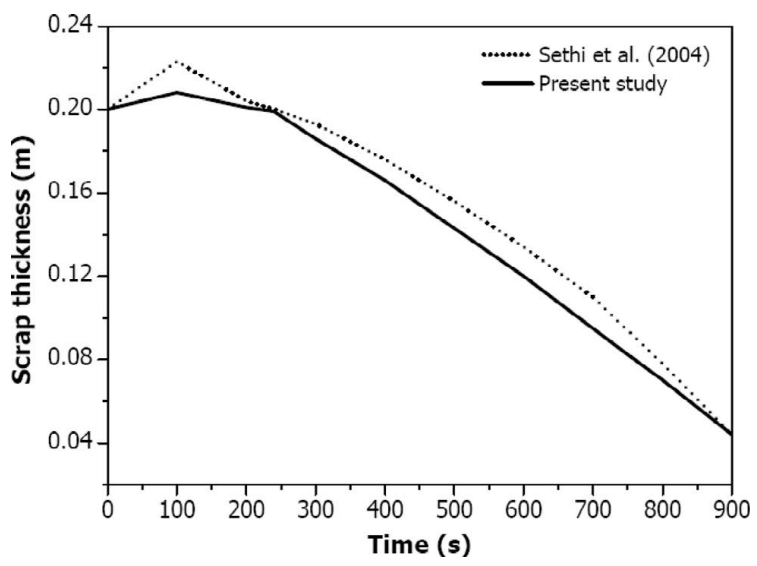

Fig. 8. The change in scrap thickness as a function of time.

stagnant). The difficulty in measuring velocity fields in steelmaking furnaces compounds the problems, as validation is very challenging.

The dimensionless analysis technique has been applied widely to calculate the heat transfer coefficient under the forced convection. Specht and Jeschar ${ }^{40)}$ developed a relationship for different types of solid particles (range of validity $\operatorname{Pr} \geq 0$ ). Szekely et $a l{ }^{38)}$ suggested that heat transfer coefficient can be related with stirring intensity under steelmaking operating conditions. The values for heat transfer coefficient lies between 3500 and $11800 \mathrm{~W} / \mathrm{m}^{2} \mathrm{~K}$. Gaye et $a l^{41)}$ also performed some plant scale experiments to determine the melting time of scrap in the top-blown, bottom-blown and combined blown processes. The suggested value for heat transfer coefficients is $17000 \mathrm{~W} / \mathrm{m}^{2} \mathrm{~K}$ for a 310 ton top-blown process. ${ }^{41)}$ The heat transfer coefficient should be modified based on the stirring conditions in the industrial practice. Irons et $a l^{42,43)}$ studied the scrap melting behavior using computation fluid dynamics for electric arc furnace steelmaking. The heat transfer model was based on phase field modelling proposed by Li et al. ${ }^{44,45)}$ This model can predict the stirring effect on the melting of individual solid scrap particles. However, this modelling technique is not currently incorporated with the global model due to its complexity. 